\title{
Legacy and Emerging Persistent Organic Pollutants in Antarctic Benthic Invertebrates near Rothera Point, Western Antarctic Peninsula
}

Artem Krasnobaev, Guillaume ten Dam, Rita Boerrigter-Eenling, Fang Peng, Stefan P. J. van Leeuwen, Simon A. Morley, Lloyd S. Peck, and Nico W. van den Brink*

Cite This: Environ. Sci. Technol. 2020, 54, 2763-2771

Read Online

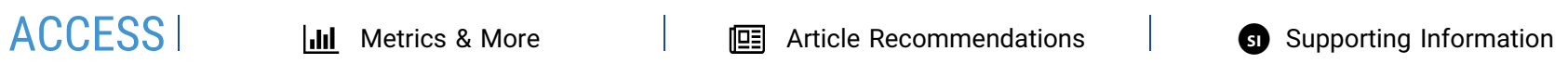

ABSTRACT: Pollutant levels in polar regions are gaining progressively more attention from the scientific community. This is especially so for pollutants that persist in the environment and can reach polar latitudes via a wide range of routes, such as some persistent organic pollutants (POPs). In this study, samples of Antarctic marine benthic organisms were analyzed for legacy and emerging POPs (polychlorinated biphenyls (PCBs), polybrominated diphenyl ethers (PBDEs), and organochlorine pesticides) to comprehensively assess their current POP concentrations and infer the potential sources of the pollutants. Specimens of five benthic invertebrate species were collected at two distinct locations near Rothera research station on the Antarctic Peninsula $\left(67^{\circ} 35^{\prime} 8^{\prime \prime} \mathrm{S}\right.$ and $\left.68^{\circ} 7^{\prime} 59^{\prime \prime} \mathrm{W}\right)$. Any impact of the nearby Rothera station as a local source of pollution appeared to be negligible. The most abundant chemicals detected were hexachlorobenzene (HCB) and BDE-209. The highest concentrations detected were in limpets and

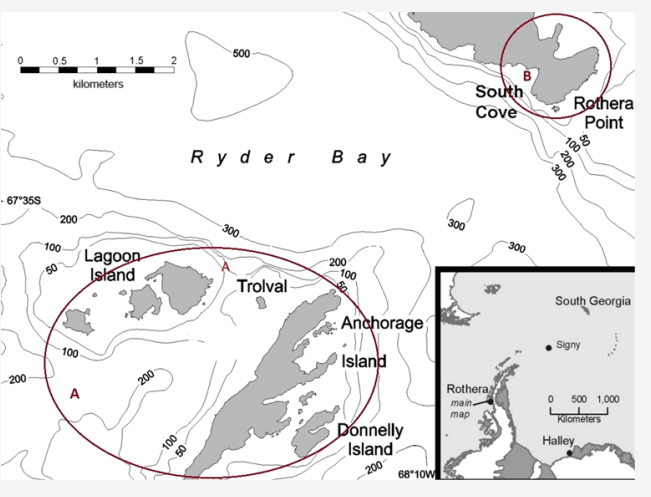
sea urchins, followed by sea stars, ascidians, and sea cucumbers. The relative congener patterns of PCBs and PBDEs were similar in all of the species. Some chemicals (e.g., heptachlor, oxychlordane, and mirex) were detected in the Antarctic invertebrates for the first time. Statistical analyses revealed that the distribution of the POPs was not only driven by the feeding traits of the species but also by the physicochemical properties of the specific compounds.

\section{INTRODUCTION}

Persistent organic pollutants (POPs) are a large group of contaminants characterized by long environmental half-lives and a high potential for accumulation in food webs and organisms. ${ }^{1}$ The more volatile POPs have the ability to be redispersed into the atmosphere after application. ${ }^{2}$ Driven by long-range atmospheric transport (LRAT), such more or less volatile POPs can travel away from the industrialized and inhabited regions of release and be deposited in remote areas, including the marine ecosystems of Antarctica. 3,4

Concentrations of POPs in Antarctic pelagic ecosystems have been studied well enough to create a comprehensive time series in different components of these ecosystems, e.g., in birds, ${ }^{5}$ mammals, ${ }^{6}$ pelagic fish, ${ }^{7,8}$ and water. ${ }^{9}$

Yet, the concentrations and fluxes of POPs in Antarctic benthic marine ecosystems are still poorly described ${ }^{5,10,11}$ due to two major challenges. First, there are logistical problems associated with the remoteness of the locations and the resources needed for the collection of samples (often including ship cruises or SCUBA diving support). Second, chemical analysis of Antarctic benthic samples is often demanding, as the concentrations of POPs are usually much lower than those in temperate and tropical areas of the world. ${ }^{12,13}$
Invertebrates are by far the most dominant macrofauna of the Antarctic marine benthic ecosystems in terms of both species number and biomass ${ }^{14}$ and can serve as important bioindicators of POPs because of their trophic diversity, slow growth rates, long life spans, and low mobility of adult animals. ${ }^{14}$ Moreover, sessile benthic organisms may provide the potential to identify local sources of POPs, such as research stations $^{15}$ and touristic ships. ${ }^{16,17}$

A few reports on POPs in various Antarctic benthic species exist, for instance around Dumont d'Urville station (Adelie Land), ${ }^{18}$ Davis station (Princess Elizabeth Land), ${ }^{19}$ and Zucchelli station (Terra Nova Bay). ${ }^{20}$ Unfortunately, the contribution of invertebrate samples to these studies was small, the proximity to the research stations as a potential contamination source was not always taken into account, and all of these studies were conducted in Eastern Antarctica. ${ }^{21}$

Because the Western Antarctic Peninsula (WAP) has experienced some of the fastest rates of climate change, the

Received: November 3, 2019

Revised: January 12, 2020

Accepted: January 17, 2020

Published: January 17, 2020 
Table 1. Overview of the Collected Samples after Pooling ${ }^{a}$

\begin{tabular}{|c|c|c|c|c|}
\hline Latin name & common name & predominant feeding behavior & total number at site Islands & total number at site Station \\
\hline Heterocucumis steineni & sea cucumber & sediment/suspension feeder ${ }^{29}$ & 12 & 16 \\
\hline Cnemidocarpa verrucosa & ascidian (sea squirt) & filter/suspension feeder ${ }^{30}$ & 15 & 14 \\
\hline Odontaster validus & sea star & carnivore $^{31}$ & 6 & 5 \\
\hline Nacella concinna & limpet & grazer $^{32}$ & - & 7 \\
\hline Sterechinus neumayeri & sea urchin & omnivore $^{33}$ & 5 & - \\
\hline
\end{tabular}

composition and abundance of species in benthic ecosystems are likely to alter. ${ }^{22-27}$ Given their complexity and diversity, this could also lead to changes in biomagnification across the entire food web. Moreover, while temporal trends in the studies of pelagic ecosystems demonstrated a clear decline in concentrations of POPs, such trends are less clear in benthic ecosystems, which makes future predictions even more difficult. $^{8}$

For a better understanding of the accumulation patterns of POPs in benthic organisms and systems, it is essential to analyze those accumulation patterns with information on species traits and properties of POPs together with details on the collection locations (proximity of nearby stations, shipping activities, etc.). To gain such insights, a study was conducted with the aim of performing a comprehensive characterization of POPs in a range of benthic invertebrate species from the WAP, representing different trophic levels, collected from different locations around Rothera research station. Therefore, this study not only quantifies current levels of POPs but is also an important step in monitoring global chemical pollutant cycles. $^{28}$

\section{MATERIALS AND METHODS}

Sample Collection. Samples of various Antarctic benthic invertebrate species, selected on the basis of diversity in physiology and feeding traits (Table 1, Appendix 1D), were collected at the beginning of February of 2017 at depths of $10-30 \mathrm{~m}$ in the northeastern part of Ryder Bay (Figure 1), next to the coast of Adelaide Island. Previous studies suggest that it is unlikely for an Antarctic station to serve as a source of

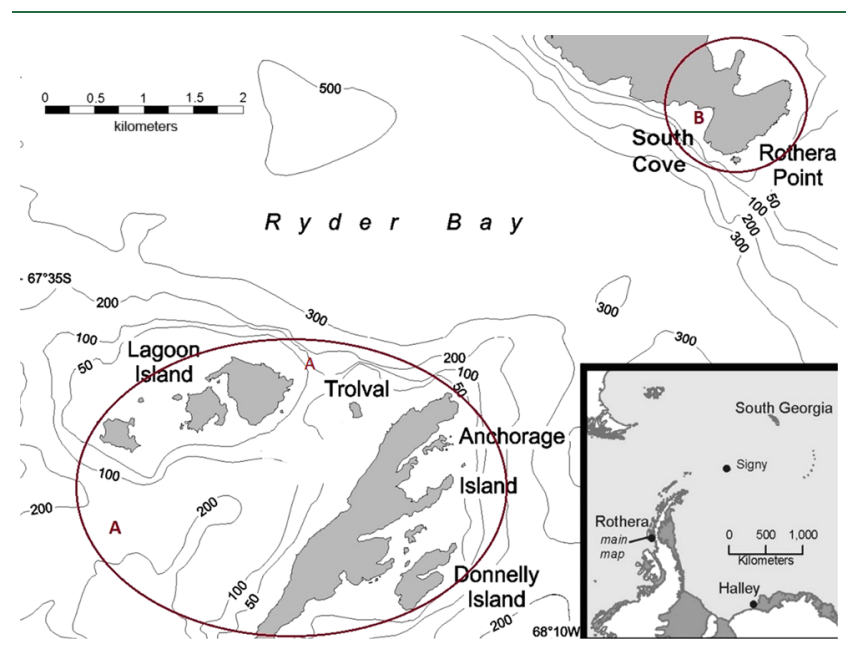

Figure 1. Map of the northeastern part of Ryder Bay with sampling locations. Site Islands (A) will principally only receive POPs by LRAT, while site Station (B) has the potential for additional contamination from the research station and air and shipping activities.
POPs for areas located farther than $3 \mathrm{~km} .{ }^{15}$ Thus, two distinct collection sites were established: site "Islands" was identified as a rarely visited area of background contamination at least $5 \mathrm{~km}$ away from the station (i.e., with POPs intake exclusively from LRAT), while the site "Station" was the area near the station, with potential for POP contamination from local sources. All of the samples were collected by SCUBA divers, packed into aluminum foil (which was first furnaced at $450{ }^{\circ} \mathrm{C}$ for $12 \mathrm{~h}$ and then cleaned with hexane) and stored in a freezer at $-20{ }^{\circ} \mathrm{C}$ until further analysis was carried out in the Netherlands.

Chemical Analysis. All of the solvents and other chemicals used in the current study were of the highest analytical grade. Glassware and metal hardware used were thoroughly precleaned, twice with hexane and twice with ethyl acetate.

Individual specimens (3-5) of limpets, sea urchins, and sea stars were pooled to ensure sufficient sample volumes for later analyses. Sea cucumbers and ascidians were large enough to be analyzed individually. All of the samples were freeze-dried at $-50{ }^{\circ} \mathrm{C}$ for at least $48 \mathrm{~h}$ and homogenized into a fine powder.

All of the samples were analyzed for polychlorinated biphenyls (PCBs; PCB 28, 52, 101, 105, 114, 118, 123, 138, $153,156,157,167,180,189)$, polybrominated diphenyl ethers (PBDEs; PBDE 17, 28, 47, 49, 66, 71, 75, 77, 85, 99, 100, 119, $138,153,154,183,190,209)$, and organochlorine pesticides (OCPs; hexachlorobenzene (HCB), hexachlorocyclohexane

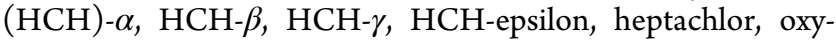
chlordane, heptachlor epoxide- $\alpha$, heptachlor epoxide- $\beta$, transchlordane, cis-chlordane, endosulfan- $\alpha$, endosulfan- $\beta, o, p^{\prime}$ DDE, $p, p^{\prime}$-DDE, $o, p^{\prime}$-DDD, and $p, p^{\prime}$-DDE, Mirex).

The complete extraction and cleanup procedure is described step-by-step in Appendix 1A. For extraction, $15 \mathrm{~mL}$ (corresponding to 3-7 $\mathrm{g}$ dry weight) of the homogenized and freeze-dried sample was transferred into $60 \mathrm{~mL}$ amber glass tubes and spiked with ${ }^{13} \mathrm{C} \mathrm{PCB}$ and ${ }^{13} \mathrm{C}$ PBDE138 standards obtained from LGC Standards (Teddington, U.K.). Distilled water was added until the total mass of the sample was $13 \mathrm{~g}$, and the sample was shaken for $3 \mathrm{~min}$. These mass and volume values were essential to establish a balance between the sample intake and the instrumental capacities of the extraction equipment. After this, $10 \mathrm{~mL}$ of ethyl acetate was added and the mixture was vigorously shaken again in an overhead shaker for at least $10 \mathrm{~min}$. This was followed by the addition of a mix of $2 \mathrm{~g}$ of sodium chloride and $4 \mathrm{~g}$ of magnesium sulfate. The samples were then centrifuged for at least $10 \mathrm{~min}$ at $350 \mathrm{~g}$. The ethyl acetate supernatant was transferred into a Turbovap tube and the procedure repeated twice, starting from the addition of another $10 \mathrm{~mL}$ of ethyl acetate. Therefore, the total volume of the extract obtained was approximately $30 \mathrm{~mL}$. The samples were concentrated in a Turbovap apparatus to $1 \mathrm{~mL}$, of which $0.1 \mathrm{~mL}$ was used for later lipid quantification, which was done gravimetrically. The rest of the extract was transferred quantitatively to a $60 \mathrm{~mL}$ amber glass vial. Each tube was washed three times with $9 \mathrm{~mL}$ 


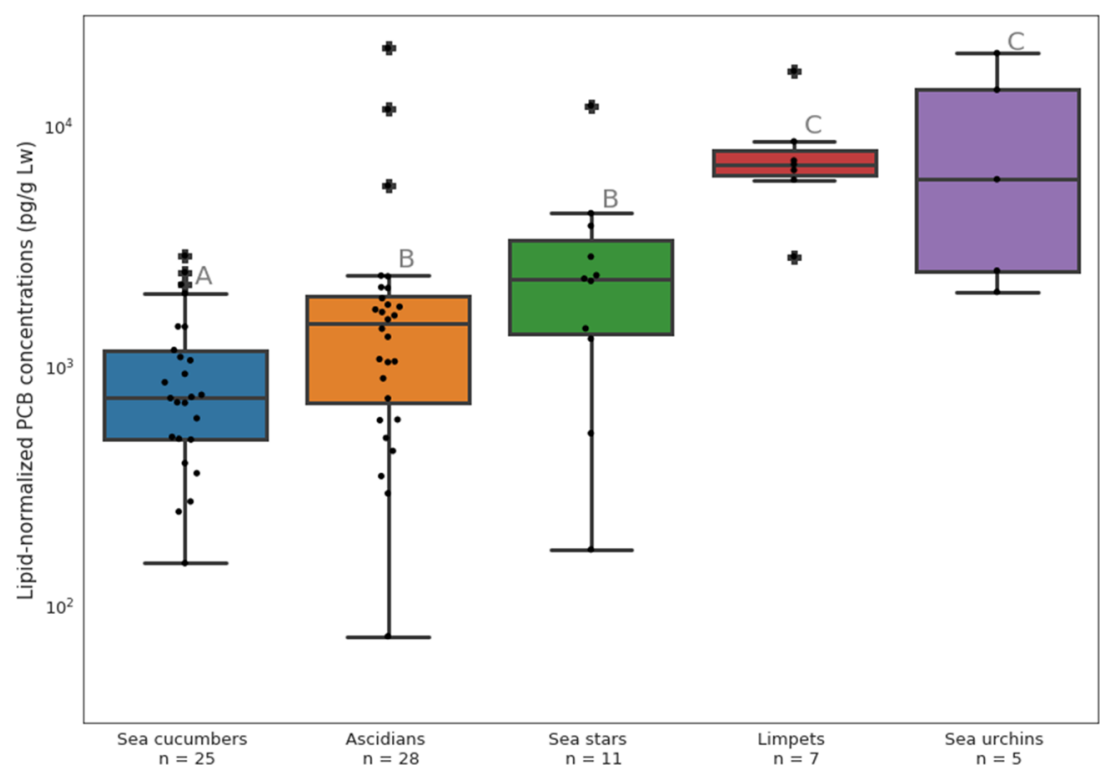

Figure 2. Boxplot of total concentrations of PCBs in $\mathrm{pg} / \mathrm{g}$ Lw. The " $n$ " quoted above denotes the number of pooled samples analyzed. The mid-line of each plot indicates the median value, the box the interquartile $(25-75 \%)$ range, and the whiskers the $95 \%$ percentile. Black dots are the original data, with black square crosses representing outliers. The plots with the same gray letter indicate no statistically significant differences.

of hexane each time, and this was combined with the extract in the $60 \mathrm{~mL}$ vials. Ten grams of $40 \%$ acidic silica was added to each sample and the sample was left overnight. After this, the hexane fraction of the sample was transferred to a new Turbovap tube, which was followed by two cycles of washing with $10 \mathrm{~mL}$ of hexane, centrifugation for $10 \mathrm{~min}$ at $350 \mathrm{~g}$, and transferring the hexane phase to the Turbovap tube. The samples were concentrated down to $1 \mathrm{~mL}$ in Turbovap and brought onto a cleanup silica column, which was packed with 1 $\mathrm{g}$ of activated silica and $8 \mathrm{~g}$ of $40 \%$ acidic silica, which were twice pre-eluted with 10 and $15 \mathrm{~mL}$ of hexane, respectively. The sample was eluted consecutively with $18 \mathrm{~mL}$ of hexane and $12 \mathrm{~mL}$ of dichloromethane. The resulting solvent mixture was evaporated in Turbovap to $0.5 \mathrm{~mL}$, and a solvent exchange to iso-octane was performed. The final $0.5 \mathrm{~mL}$ of extract in isooctane was stored at $-20{ }^{\circ} \mathrm{C}$ until measurements were made. Some OCPs (e.g., dieldrin and endrin) degrade under acidic conditions (i.e., acidic silica) used in this cleanup approach and are therefore not reported in this study.

PCBs and PBDEs were quantified using a Magnetic Sector Autospec gas chromatograph-high-resolution mass spectrometer (GC-HRMS) from Waters (Manchester, U.K.) equipped with an Agilent 6890 gas chromatograph (Santa Clara). OCPs were measured by an Agilent 7010B triple quadrupole coupled with an Agilent 7890 gas chromatograph (Santa Clara). DB$5 \mathrm{MS} 60 \mathrm{~m} \times 0.25 \mathrm{~mm} \times 0.25 \mu \mathrm{m}$ fused silica capillary column from Agilent J\&W (Folson) was used for PCB analysis, while CL-Pesticide $30 \mathrm{~m} \times 0.25 \mathrm{~mm} \times 0.25 \mu \mathrm{m}$ from Restek (Bellefonte) was fitted for the analysis of PBDEs and OCPs. Measurements were conducted at the Wageningen Food Safety Research (WFSR) laboratories in Wageningen, the Netherlands. For further details on the GC methods, see Appendix $1 \mathrm{~B}$.

For quality assurance/quality control (QA/QC) (Appendix $2)$, each measurement batch contained 10 samples, a procedural blank, and a sample of a certified reference material (SRM 1947 Lake Michigan fish tissue, National Institute of Standards and Technology). For extra QC, the samples were spiked with ${ }^{13} \mathrm{C}$-labeled PCBs (all analyzed congeners) and ${ }^{13}$ C-PBDE-138.

Limits of quantification (LOQs) were calculated as two times the concentration of the compound in the extract of the corresponding blank sample. The concentrations in the samples were adjusted for blanks, while the recovery rates (Appendix 2) were used exclusively for QC (i.e., they were not used for adjustment).

Data Analysis. All of the data analysis was completed using a Jypiter notebook with Python 3 and Canoco 5 software. The values below detection limits were not considered in the statistical analysis and set to zero when calculating total concentrations.

The detailed description of statistical methods is presented in Appendix 3. Mann-Whitney-Wilcoxon (MWW) (another name Mann-Whitney $U$ ) test was used to assess whether differences between samples were significant $(\alpha=0.05)$, which was Bonferonni-adjusted when exploring site-specific differences (see Appendix 3 for rationale). Principal component analysis (PCA) and its derivative double constrained principal component analysis (dc-PCA) were used to investigate accumulation patterns among species and to identify which physicochemical properties of POPs control their accumulation patterns. $^{34}$ The values of these physicochemical properties of the different POPs values are presented in Appendix 5.

All results in the current study are expressed as picogram per gram lipid (pg/g Lw). For comparison with other studies, where concentrations were expressed on a wet or dry weight basis, the data were adjusted to lipid weight basis using average lipid contents of the species determined gravimetrically in the current study.

\section{RESULTS AND DISCUSSION}

The results for concentrations of PCBs, PBDEs, and OCPs in individual samples can be found in Appendixes 4A, 4B, and 4C, respectively. The lipid content of the samples did not show any interspecific differences (Appendix 1). 


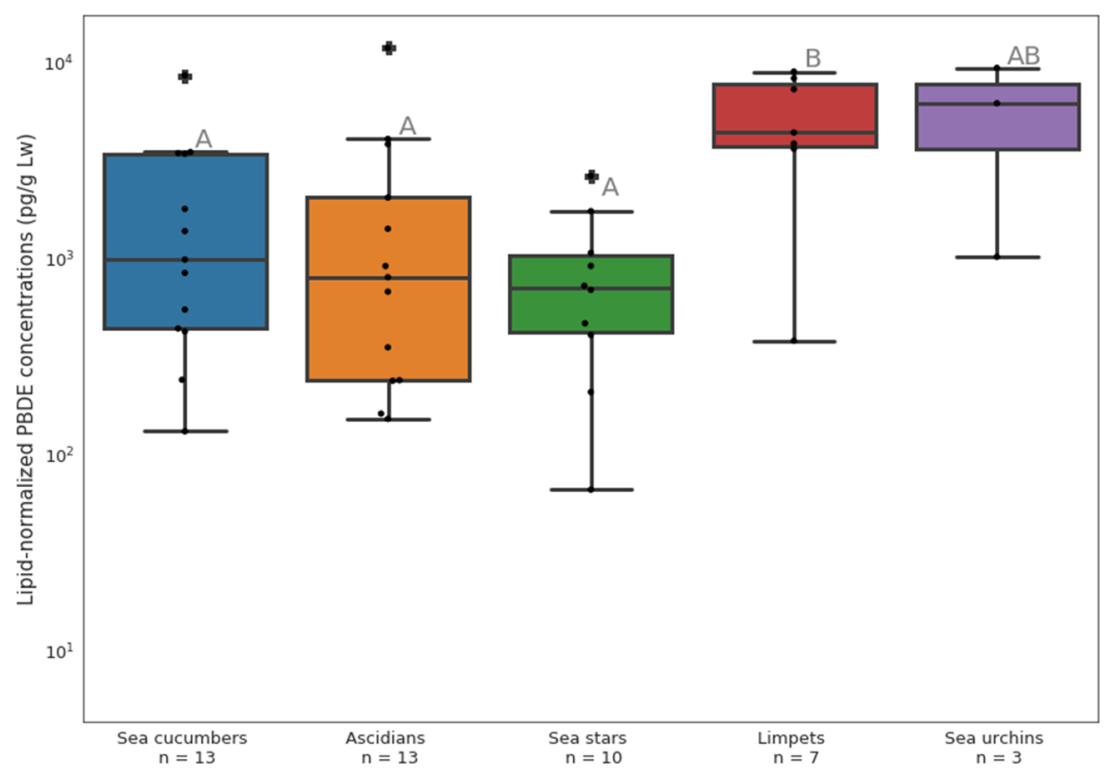

Figure 3. Boxplot of total concentrations of PBDEs in $\mathrm{pg} / \mathrm{g} \mathrm{Lw}$. The $n$ quoted above denotes the number of pooled samples analyzed. The mid-line of each plot indicates the median value, the box the interquartile $(25-75 \%)$ range, and the whiskers the $95 \%$ percentile. Black dots are the original data, with black square crosses representing outliers. The plots with the same gray letter indicate no statistically significant differences.

Rothera Station as a Possible Source of POP Pollution. There were no significant differences between samples collected near Rothera station (site Station) and the islands in Ryder Bay (site Islands) (MWW test with Bonferonni correction; Appendix 3). This is in contrast to previous research in Antarctica around McMurdo station, which identified differential PBDE and PCB congener patterns (linked to the composition of industrial mixtures such as Arochlor) as clear signs of local contamination. ${ }^{35}$ Results indicate that Rothera station and associated operations have not resulted in a significant release of the POPs studied. Since there were no statistically significant differences between the locations, all of the data sets were merged and used together for further statistical analyses and discussion of species-specific accumulation patterns.

Species-Specific Concentrations. PCBs. The total PCB concentrations in the different species are presented in Figure 2

Overall, the results show that $\mathrm{PCB}$ concentrations vary significantly among species in the current study. Sea cucumbers had the lowest PCB concentrations, which were significantly lower than those in all other species. The concentrations in ascidians were higher than in the sea cucumbers, but their variance was higher because of three noticeable outliers. Concentrations in the sea stars were similar to the ascidians, while limpets had significantly higher PCB concentrations than the sea stars. The concentrations in urchins were not significantly different from the limpets but had a larger variance.

The concentrations measured in the current study were all well below concentrations found in the same or similar species in previous studies in Antarctica: PCB concentrations in the limpets were up to 30 times lower than the values reported in the same species from Princess Elizabeth Land in 2018, ${ }^{19}$ and in urchins they were up to 30 or even 60 times lower than those from Adélie Land ${ }^{18}$ in 2009 and Princess Elizabeth Land $^{19}$ in 1995, respectively.

There may be several reasons for the consistently low PCB concentrations. First, the benthic invertebrates near Rothera may simply not have been exposed to PCBs as those from other studies. Second, concentrations in the other studies may have been influenced by unrecognized local inputs of PCBs. For example, an earlier report ${ }^{20}$ indicated an order of magnitude difference in PCB concentrations found in the same benthic invertebrate species, collected at the same sampling site, but at different time points during the season, with elevated concentrations corresponding to the periods of increased station activity.

Concentrations in the sea stars O. validus of the current study were approximately two times lower than previously found in the sea stars Saliasterias brachiata from Adélie Land in 2013. ${ }^{18}$ The most likely explanation lies in a different feeding behavior: while the former is a carnivore, the latter is a necrophagous. $^{36}$

The relative concentrations of the individual PCB congeners were similar across the species (Appendix 4A). These outcomes followed previous findings, ${ }^{20}$ which quantified penta- and hexa-CBs to account for approximately $60 \%$ of all PCB concentrations. However, there was a slight disagreement with a smaller study on sea stars and sea urchins, ${ }^{18}$ which showed a predominance of penta-CBs.

PBDEs. Concentrations of PBDEs in limpets were significantly higher (Figure 3) than those in sea cucumbers, ascidians, and sea stars, while the differences between sea urchins and all the other species were not significant, possibly due to the low number of samples $(n=3)$. This is different from the trends seen for PCBs (Figure 1), which, however, is in close agreement with recent experimental work on accumulation patterns of PCBs and PBDEs in invertebrates with different feeding behaviors, which showed that concentrations of $\mathrm{PCBs}$ tended to increase more rapidly than that of PBDEs with increasing trophic level. ${ }^{37}$

BDE-209 accounted for more than $90 \%$ of the total PBDE concentrations for all species (Appendix 4B). Although other PBDE congeners showed much lower concentrations, their accumulation pattern is similar to that of BDE-209 (Appendix $4 B)$. 

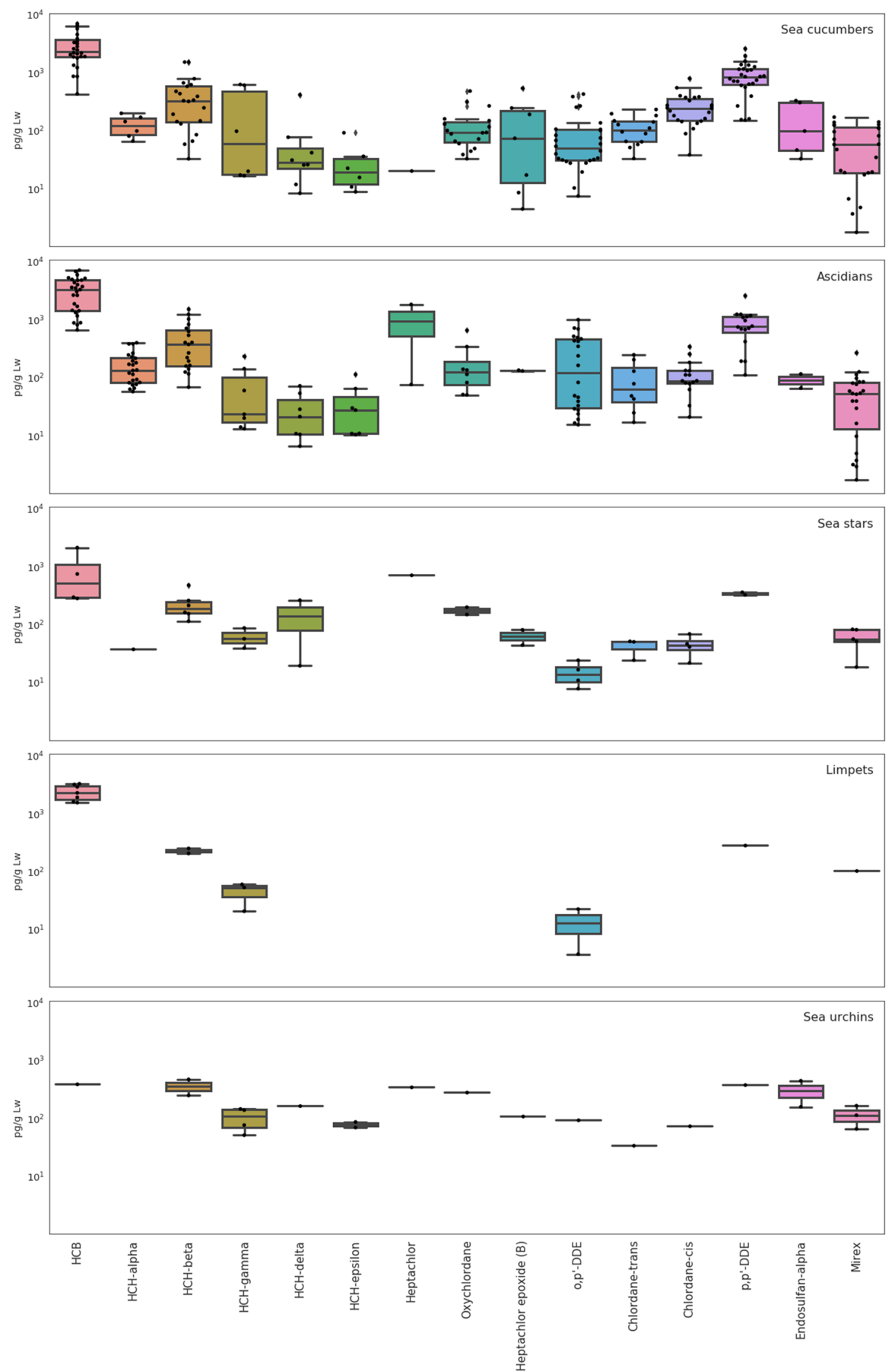

Figure 4. OCP concentrations in five Antarctic benthic species in $\mathrm{pg} / \mathrm{g} \mathrm{Lw}$. The mid-line of each plot indicates the median value, the box shows the interquartile range, and the whiskers are the $95 \%$ percentile range. The blank spaces indicate no data, as all measurements were below the detection limit.

Because BDE-209 may dibrominate into more toxic congeners during LRAT and in the environment, ${ }^{38,39}$ its accumulation in benthic animals deserves closer attention. Overall, there is a lot of conflicting information about BDE- 
209 in the Antarctic environment. While some studies in biota were not able to detect it all, ${ }^{40,41}$ it was the predominant congener in long-term air monitoring. ${ }^{42}$ Historically, BDE-209 input in Antarctica was attributed to local activities; ${ }^{35}$ however, the fact that its high concentrations were currently found in an area with very little or no human activity (site Islands) provides evidence that atmospheric inputs also play an important role in fluxes of BDE-209 in Antarctica. Such a predominance of BDE-209 over other congeners in sea stars and urchins was also previously reported in Adélie Land in 2013, ${ }^{18}$ and that showed similar total PBDEs concentrations. A study from McMurdo Sound in 2008 stressed the contribution of BDE-209 to the overall PBDE burden, but the total concentrations were up to 5 times higher ${ }^{35}$ than those reported here. Results from our and other studies indicate that BDE-209 may be released in the Antarctic marine system by atmospheric deposition, resulting from LRAT, without the need for local sources.

Previous efforts were dedicated to determining the general temporal trends of PBDEs in different parts of Antarctic ecosystems, which demonstrated that in contrast to decreasing trends in the Arctic, the PBDE concentrations in Antarctica remained constant. ${ }^{41}$ However, not all of those articles reported BDE-209, therefore potentially missing the most important congener. The concentrations in the current study were comparable to those found 10 years earlier, ${ }^{18}$ which would support the general consensus of the combined studies that, even when BDE-209 is accounted for, the total PBDE concentrations did not seem to change over time in the Antarctic system.

OCPs. In all of the species studied, the most prevalent OCP was $\mathrm{HCB}$, which can be expected for the Antarctic biota due to its high atmospheric mobility and preferential condensation in cold regions. ${ }^{7,43}$ Moreover, HCB is known to accumulate in invertebrates. $^{44}$ The concentrations of HCB did not differ significantly among the species (Figure 4). This is in good agreement with previous research, which indicated a lack of HCB biomagnification across marine species in different trophic levels from Antarctica. ${ }^{45}$ Generally, the currently measured HCB concentrations were 10-30 times lower in comparison to HCB levels in invertebrates measured in 1993 at Terra Nova Bay, ${ }^{46}$ which implies a decrease in $\mathrm{HCB}$ concentrations over time. On the other hand, a more recent study in Adélie Land from 2013 was not able to detect any HCB in invertebrates at all. ${ }^{18}$ The explanation likely lies in the more frequent snowfalls around the WAP, ${ }^{47-50}$ which could have amplified HCB in the current study. ${ }^{51,52}$

The second most abundant OCP was $p, p^{\prime}$-DDE. There were no statistically significant differences in its concentrations among species except for the sea cucumbers, which contained significantly more $p, p^{\prime}$-DDE than the other species (Figure 4 and Appendix 3). The $p, p^{\prime}$-DDE concentrations were similar to those reported in a previous study from 1993 on bivalves in Terra Nova Bay. ${ }^{46} p, p^{\prime}$-DDE concentrations measured in the Artic in 2000 were $10-20$ higher in waved whelks ${ }^{53}$ than in the invertebrates in the current study. Interestingly, no $p, p^{\prime}$-DDT could be detected in any of the current species, which may signify its complete transformation into $p, p^{\prime}$-DDE. This would indicate no recent inputs of $p, p^{\prime}$-DDT into the local marine environment of Ryder Bay. This may imply a very limited input of $p, p^{\prime}$-DDT from glacial run-off, ${ }^{54}$ as has been suggested as a contemporary source of OCPs into Antarctic ecosystems, although its actual extent is debated ${ }^{55}$ and thus supported by the current study.

HCB and $p, p^{\prime}$-DDE were followed by the chlordane (mainly cis-chlordane) and $\mathrm{HCH}$ (mainly $\mathrm{HCH}-\beta$ ) groups, Heptachlor, Mirex, and Endosulfan. It is the first time these compounds were measured in Antarctic invertebrates, and their concentrations were lower than those reported in the Artic. ${ }^{53}$ Overall, there were few interspecific differences in OCP concentrations (Appendix 3). Notable exceptions were heptachlor and oxychlordane, which were detected at significantly higher concentrations in sea cucumbers than in other species, which may result from them being suspension feeders.

Drivers of Species-Specific Accumulation. A dc-PCA was performed on the data on measured concentrations of POPs to extract insights of the interspecific accumulation patterns (Figure 5) and to link them with the biological traits of the species and physicochemical properties of the compounds (Figure 6).

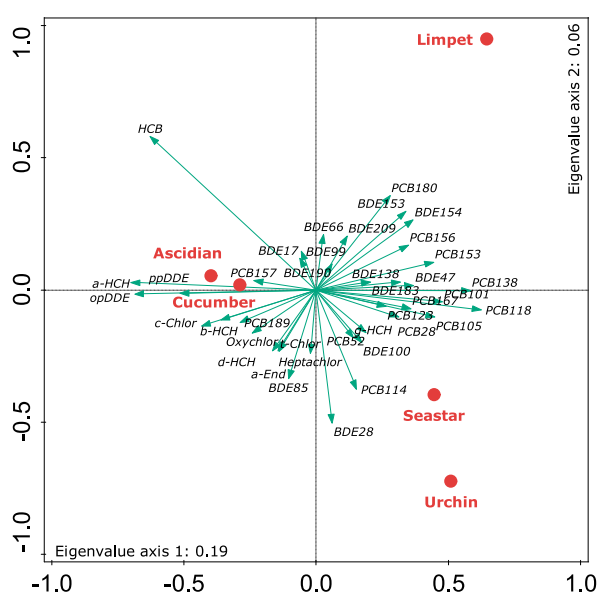

Figure 5. Bi-plot of dc-PCA-related concentrations of POPs (green arrows) and species (red dots) $(\lambda 1=0.19$ and $\lambda 2=0.06)$.

The eigenvalue of axis 1 was 0.194 (statistics pseudo $F_{\text {prob}}$ : $3.1, p=0.002$ ) and the one for axis 2 was 0.056 (statistics of combined axes: pseudo $F_{\text {prob }}: 5.9, p=0.002$ ). This dc-PCA

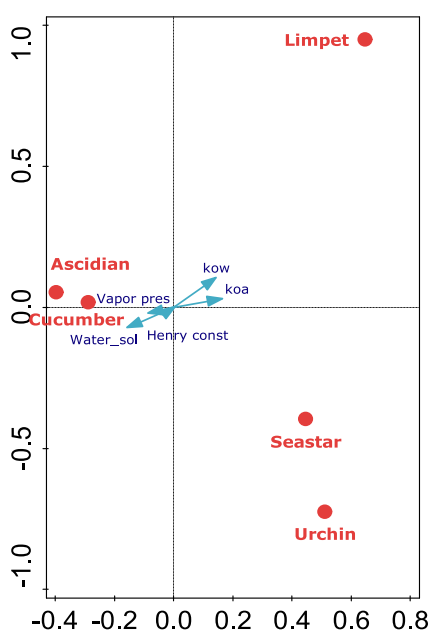

Figure 6. Bi-plot of dc-PCA-related species (red dots) and properties of POPs (blue arrows) $(\lambda 1=0.059$ and $\lambda 2=0.026)$. 
indicates that limpets contained relatively high concentrations of higher halogenated PCBs and PBDEs, while ascidians and cucumbers accumulated more OCPs (especially $\mathrm{HCB}$ ), with sea stars and urchins being in between.

The dc-PCA on the data, constrained by physicochemical properties of POPs (Kow, Koa, Henry's constant, water solubility, and vapor pressure) (Figure 6), indicates that these properties were significantly related to the concentrations of POPs (pseudo $F_{\text {prob }}: 2.7, p=0.008$ ).

Limpets contained more POPs with higher Kow and Koa (Appendix 5), which was likely related to the grazing feeding behavior of this species, as POPs with high Kow can be expected to accumulate in the lipophilic particles limpets feed on. ${ }^{32}$ Furthermore, it may be related to the fact that limpets may have limited dermal exchange with the water because of their shell. This may limit the uptake of more water-soluble POPs, i.e., the ones with lower Kow. Ascidians and sea cucumbers contained more compounds that were relatively water-soluble, which corresponded to their greater surface area of exposed soft tissue and their respective filter and suspensionfeeding modes. Finally, sea stars and urchins occupied (again) somewhat middle ground. This was possibly related to their respective predatory and omnivorous behavior, ${ }^{31,33}$ which includes diet items exposed to either foodborne POPs (with high Kow) or waterborne POPs (with low Kow). This mechanism is supported by previous attempts to explain differences in uptake between species. ${ }^{45,51}$ The structure of dermis can be another factor controlling the bioconcentration of POPs: the softer dermis of sea cucumbers ${ }^{56}$ and ascidians ${ }^{57}$ may lead to more intensive accumulation of POPs in these species when compared to sea urchins, whose dermis is harder. $^{31,58,59}$

Overall, specific feeding behavior and the dermis of the species, and Kow and Koa of particular POPs, influence the concentration of these compounds in examined animals.

\section{ASSOCIATED CONTENT}

\section{SI Supporting Information}

The Supporting Information is available free of charge at https://pubs.acs.org/doi/10.1021/acs.est.9b06622.

Details on chemical analysis and sample information (PDF)

Chemical analysis and sample information; complete extraction and clean-up procedure; instrumental settings for analysis of POPs; lipid content in individual species; additional information on the sampled species (PDF)

QA/QC (XLSX)

Statistics, explanation of Bonferonni correction (PDF)

Concentration of PCBs in individual samples (XLSX)

Concentration of PBDEs in individual samples (XLSX)

Concentration of OCPs in individual samples (XLSX)

Physicochemical properties of measured POPs and their relation to the concentration in benthic animals (XLSX)

\section{AUTHOR INFORMATION}

\section{Corresponding Author}

Nico W. van den Brink - Sub-Department of Toxicology, Wageningen University, NL 6700 EA Wageningen, the Netherlands; Email: nico.vandenbrink@wur.nl

\section{Authors}

Artem Krasnobaev - Sub-Department of Toxicology,

Wageningen University, NL 6700 EA Wageningen, the Netherlands; 10 orcid.org/0000-0002-7843-0292

Guillaume ten Dam - Wageningen Research, Wageningen Food Safety Research (WFSR), NL 6700 AE Wageningen, the Netherlands; DSP-systems, 6718 XR Ede, the Netherlands

Rita Boerrigter-Eenling - Wageningen Research, Wageningen Food Safety Research (WFSR), NL 6700 AE Wageningen, the Netherlands

Fang Peng - Luxembourg Institute of Health, 1445 Strassen, Luxembourg

Stefan P. J. van Leeuwen - Wageningen Research, Wageningen Food Safety Research (WFSR), NL 6700 AE Wageningen, the Netherlands; O orcid.org/0000-0003-4847-0768

Simon A. Morley - Natural Environment Research Council (NERC), British Antarctic Survey, Cambridge CB3 OET, United Kingdom

Lloyd S. Peck - Natural Environment Research Council (NERC), British Antarctic Survey, Cambridge CB3 OET, United Kingdom

Complete contact information is available at:

https://pubs.acs.org/10.1021/acs.est.9b06622

\section{Notes}

The authors declare no competing financial interest.

\section{ACKNOWLEDGMENTS}

The authors acknowledge the help of the British Antarctic Survey (BAS) with infrastructure and coordination. The BAS divers are acknowledged for their support in sampling. We thank Willie Hijman and Guido van der Weg for their help with measurements with PCBs and PBDEs. We express our gratitude toward the Netherlands Organisation for Scientific Research (NWO) (grant 866.14.104) for financing this project.

\section{REFERENCES}

(1) Kelly, B. C.; Ikonomou, M. G.; Blair, J. D.; Morin, A. E.; Gobas, F. A. P. C. Food Web-Specific Biomagnification of Persistent Organic Pollutants. Science 2007, 317, 236-239.

(2) Jones, K. C.; de Voogt, P. Persistent Organic Pollutants (POPs): State of the Science. Environ. Pollut. 1999, 100, 209-221.

(3) Andreas, B.; Donald, M.; Michael, M.; Frank, W.; Webster, E. Assessing long-range transport potential of persistent organic pollutants. Environ. Sci. Technol. 2000, 34, 699-703.

(4) Bargagli, R. Environmental Contamination in Antarctic Ecosystems. Sci. Total Environ. 2008, 400, 212-226.

(5) Ellis, D. S.; Cipro, C. V. Z.; Ogletree, C. A.; Smith, K. E.; Aronson, R. B. A 50-Year Retrospective of Persistent Organic Pollutants in the Fat and Eggs of Penguins of the Southern Ocean. Environ. Pollut. 2018, 241, 155-163.

(6) Trumble, S. J.; Robinson, E. M.; Noren, S. R.; Usenko, S.; Davis, J.; Kanatous, S. B. Assessment of Legacy and Emerging Persistent Organic Pollutants in Weddell Seal Tissue (Leptonychotes Weddellii) near McMurdo Sound, Antarctica. Sci. Total Environ. 2012, 439, 275283.

(7) Goerke, H.; Weber, K.; Bornemann, H.; Ramdohr, S.; Plötz, J. Increasing Levels and Biomagnification of Persistent Organic Pollutants (POPs) in Antarctic Biota. Mar. Pollut. Bull. 2004, 48, 295-302.

(8) van den Brink, N. W.; Riddle, M. J.; van den Heuvel-Greve, M.; van Franeker, J. A. Contrasting Time Trends of Organic Contaminants in Antarctic Pelagic and Benthic Food Webs. Mar. Pollut. Bull. 2011, 62, 128-132. 
(9) Galbán-Malagón, C. J.; Del Vento, S.; Berrojalbiz, N.; Ojeda, M.J.; Dachs, J. Polychlorinated Biphenyls, Hexachlorocyclohexanes and Hexachlorobenzene in Seawater and Phytoplankton from the Southern Ocean (Weddell, South Scotia, and Bellingshausen Seas). Environ. Sci. Technol. 2013, 47, 5578-5587.

(10) Bates, M. L.; Bengtson Nash, S. M.; Hawker, D. W.; Shaw, E. C.; Cropp, R. A. The Distribution of Persistent Organic Pollutants in a Trophically Complex Antarctic Ecosystem Model. J. Mar. Syst. 2017, 170, 103-114.

(11) Weber, K.; Goerke, H. Persistent Organic Pollutants (POPs) in Antarctic Fish: Levels, Patterns, Changes. Chemosphere 2003, 53, 667-678.

(12) Fuoco, R.; Capodaglio, G.; Muscatello, B.; Radaelli, M. (SCAR Action Group on Environmental Contamination in Antarctica). Persistent Organic Pollutants (POPs) in the Antarctic Environment: A Review of Findings; SCAR: Cambridge, 2017.

(13) Bengtson Nash, S. Persistent Organic Pollutants in Antarctica: Current and Future Research Priorities. J. Environ. Monit. 2011, 13, 497.

(14) Peck, L. Antarctic Marine Biodiversity: Adaptations, Environments and Responses to Change. Oceanogr. Mar. Biol. An Annu. Rev. 2018, 56, 105-236.

(15) Wild, S.; McLagan, D.; Schlabach, M.; Bossi, R.; Hawker, D.; Cropp, R.; King, C. K.; Stark, J. S.; Mondon, J.; Nash, S. B. An Antarctic Research Station as a Source of Brominated and Perfluorinated Persistent Organic Pollutants to the Local Environment. Environ. Sci. Technol. 2015, 49, 103-112.

(16) Cressey, D. Polar Code Protects Ships and Species in Icy Waters. Nature 2014, DOI: 10.1038/nature.2014.16402.

(17) Enzenbacher, D. J. Antarctic Tourism and Environmental Concerns. Mar. Pollut. Bull. 1992, 25, 258-265.

(18) Goutte, A.; Chevreuil, M.; Alliot, F.; Chastel, O.; Cherel, Y.; Eléaume, M.; Massé, G. Persistent Organic Pollutants in Benthic and Pelagic Organisms off Adélie Land, Antarctica. Mar. Pollut. Bull. 2013, 77, 82-89.

(19) Ko, F.-C.; Pan, W.-L.; Cheng, J.-O.; Chen, T.-H.; Kuo, F.-W.; Kao, S.-J.; Chang, C.-W.; Ho, H.-C.; Wang, W.-H.; Fang, L.-S. Persistent Organic Pollutants in Antarctic Notothenioid Fish and Invertebrates Associated with Trophic Levels. PLoS One 2018, 13, No. e0194147.

(20) Grotti, M.; Pizzini, S.; Abelmoschi, M. L.; Cozzi, G.; Piazza, R.; Soggia, F. Retrospective Biomonitoring of Chemical Contamination in the Marine Coastal Environment of Terra Nova Bay (Ross Sea, Antarctica) by Environmental Specimen Banking. Chemosphere 2016, $165,418-426$.

(21) Corsolini, S. Industrial Contaminants in Antarctic Biota. J. Chromatogr. A 2009, 1216, 598-612.

(22) Moreau, S.; Mostajir, B.; Bélanger, S.; Schloss, I. R.; Vancoppenolle, M.; Demers, S.; Ferreyra, G. A. Climate Change Enhances Primary Production in the Western Antarctic Peninsula. Glob. Chang. Biol. 2015, 21, 2191-2205.

(23) Ashton, G. V.; Morley, S. A.; Barnes, D. K. A.; Clark, M. S.; Peck, L. S. Warming by $1{ }^{\circ} \mathrm{C}$ Drives Species and Assemblage Level Responses in Antarctica's Marine Shallows. Curr. Biol. 2017, 27, 2698-2705.e3.

(24) Barnes, D. K. A. Antarctic Sea Ice Losses Drive Gains in Benthic Carbon Drawdown. Curr. Biol. 2015, 25, R789-R790.

(25) Peck, L. S.; Barnes, D. K. A.; Cook, A. J.; Fleming, A. H.; Clarke, A. Negative Feedback in the Cold: Ice Retreat Produces New Carbon Sinks in Antarctica. Glob. Chang. Biol. 2010, 16, 2614-2623.

(26) Kennicutt, M. C.; Bromwich, D.; Liggett, D.; Njåstad, B.; Peck, L.; Rintoul, S. R.; Ritz, C.; Siegert, M. J.; Aitken, A.; Brooks, C. M.; Cassano, S.; Chaturvedi, D.; Dodds, K.; Golledge, N.; Le Bohec, C.; Murray, A.; Raphael, M.; Yang, H.; Chown, S.; et al. Sustained Antarctic Research: A 21st Century Imperative. One Earth 2019, 1, 95-113.

(27) Henley, S. F.; Schofield, O. M.; Hendry, K. R.; Schloss, I. R.; Steinberg, D. K.; Moffat, C.; Peck, L. S.; Costa, D. P.; Bakker, D. C. E.; Hughes, C.; Rozema, P.; Ducklow, H.; Abele; Doris; Stefels, J.; van
Leeuwe, M.; Brussaard, C.; Buma, A.; Kohut, J.; Sahade, R.; Friedlaender, A.; Stammerjohn, S.; Venables, H.; Meredith, P.; et al. Variability and Change in the West Antarctic Peninsula Marine System: Research Priorities and Opportunities. Prog. Oceanogr. 2019, 173, 208-237.

(28) Teran, T.; Lamon, L.; Marcomini, A. Climate Change Effects on POPs' Environmental Behaviour: A Scientific Perspective for Future Regulatory Actions. Atmos. Pollut. Res. 2012, 3, 466-476.

(29) Sun, J.; Zhang, L.; Pan, Y.; Lin, C.; Wang, F.; Kan, R.; Yang, H. Feeding Behavior and Digestive Physiology in Sea Cucumber Apostichopus Japonicus. Physiol. Behav. 2015, 139, 336-343.

(30) Tatián, M.; Sahade, R.; Kowalke, J.; Kivatinitz, S.; Esnal, G. Food Availability and Gut Contents in the Ascidian Cnemidocarpa Verrucosa at Potter Cove, Antarctica. Polar Biol. 2002, 25, 58-64.

(31) Peck, L. S.; Clark, M. S.; Dunn, N. I. Morphological Variation in Taxonomic Characters of the Antarctic Starfish Odontaster Validus. Polar Biol. 2018, 41, 2159-2165.

(32) Brêthes, J.-C.; Ferreyra, G.; de la Vega, S. Distribution, Growth and Reproduction of the Limpet Nacella (Patinigera) Concinna (Strebel 1908) in Relation to Potential Food Availability, in Esperanza Bay (Antarctic Peninsula). Polar Biol. 1994, 14, 161-170.

(33) Brockington, S.; Clarke, A.; Chapman, A. L. G. Seasonality of Feeding and Nutritional Status during the Austral Winter in the Antarctic Sea Urchin Sterechinus Neumayeri. Mar. Biol. 2001, 139, 127-138.

(34) van der Maaten, L.; Hinton, G. Visualizing Data Using T-SNE. J. Mach. Learn. Res. 2008, 9, 2579-2605.

(35) Hale, R. C.; Kim, S. L.; Harvey, E.; La Guardia, M. J.; Mainor, T. M.; Bush, E. O.; Jacobs, E. M. Antarctic Research Bases: Local Sources of Polybrominated Diphenyl Ether (PBDE) Flame Retardants. Environ. Sci. Technol. 2008, 42, 1452-1457.

(36) Michel, L. N.; Danis, B.; Dubois, P.; Eleaume, M.; Fournier, J.; Gallut, C.; Jane, P.; Lepoint, G. Increased Sea Ice Cover Alters Food Web Structure in East Antarctica. Sci. Rep. 2019, 9, No. 8062.

(37) Frouin, H.; Jackman, P.; Dangerfield, N. D.; Ross, P. S. Effects of Feeding Strategy, Sediment Characteristics, and Chemical Properties on Polychlorinated Biphenyl and Polybrominated Diphenyl Ether Bioaccumulation from Marine Sediments in Two Invertebrates. Arch. Environ. Contam. Toxicol. 1973, 256-269.

(38) Zheng, B.; Zhao, X.; Ni, X.; Ben, Y.; Guo, R.; An, L. Bioaccumulation Characteristics of Polybrominated Diphenyl Ethers in the Marine Food Web of Bohai Bay. Chemosphere 2016, 150, 424430.

(39) Viganò, L.; Roscioli, C.; Guzzella, L. Decabromodiphenyl Ether (BDE-209) Enters the Food Web of the River Po and Is Metabolically Debrominated in Resident Cyprinid Fishes. Sci. Total Environ. 2011, 409, 4966-4972.

(40) Wang, P.; Zhang, Q.; Wang, T.; Chen, W.; Ren, D.; Li, Y.; Jiang, G. PCBs and PBDEs in Environmental Samples from King George Island and Ardley Island, Antarctica. RSC Adv. 2012, 2 (4), 1350-1355. DOI: 10.1039/C1RA00462J.

(41) Markham, E.; Brault, E. K.; Khairy, M.; Robuck, A. R.; Goebel, M. E.; Cantwell, M. G.; Dickhut, R. M.; Lohmann, R. Time Trends of Polybrominated Diphenyl Ethers (PBDEs) in Antarctic Biota. ACS Omega 2018, 3, 6595-6604.

(42) Wang, P.; Li, Y.; Zhang, Q.; Yang, Q.; Zhang, L.; Liu, F.; Fu, J.; Meng, W.; Wang, D.; Sun, H.; et al. Three-Year Monitoring of Atmospheric PCBs and PBDEs at the Chinese Great Wall Station, West Antarctica: Levels, Chiral Signature, Environmental Behaviors and Source Implication. Atmos. Environ. 2017, 150, 407-416.

(43) Lakaschus, S.; Weber, K.; Wania, F.; Bruhn, R.; Schrems, O. The Air-Sea Equilibrium and Time Trend of Hexachlorocyclohexanes in 476 the Atlantic Ocean between the Arctic and Antarctica. Environ. Sci. Technol. 36, 138 145. DOI: 10.1021/ES010211J.

(44) Moermond, C. T.; Verbruggen, E. M. An Evaluation of Bioaccumulation Data for Hexachlorobenzene to Derive Water Quality Standards According to the EU-WFD Methodology. Integr. Environ. Assess. Manag. 2013, 9, 87-97. 
(45) Corsolini, S.; Sarà, G. The Trophic Transfer of Persistent Pollutants (HCB, DDTs, PCBs) within Polar Marine Food Webs. Chemosphere 2017, 177, 189-199.

(46) Focardi, S.; Bargagli, R.; Corsolini, S. Organochlorines in Antarctic Marine Food Chain at Terranova Bay (Ross Sea). Korea J. Polar Res. 4, 7377.

(47) Bromwich, D. H.; Nicolas, J. P.; Monaghan, A. J. An Assessment of Precipitation Changes over Antarctica and the Southern Ocean since 1989 in Contemporary Global Reanalyses. J. Clim. 2011, 24, 4189-4209.

(48) Shanklin, J.; Moore, C.; Colwell, S. Meteorological Observing and Climate in the British Antarctic Territory and South Georgia:

Part 2. Weather 2009, 64, 171-177.

(49) Bertler, N. A. N.; Conway, H.; Dahl-Jensen, D.; Emanuelsson, D. B.; Winstrup, M.; Vallelonga, P. T.; Lee, J. E.; Brook, E. J.; Severinghaus, J. P.; Fudge, T. J.; et al. The Ross Sea Dipole Temperature, Snow Accumulation and Sea Ice Variability in the Ross Sea Region, Antarctica, over the Past 2700 Years. Clim. Past 2018, 14, 193-214.

(50) Genthon, C.; Berne, A.; Grazioli, J.; Durán Alarcón, C.; Praz, C.; Boudevillain, B. Precipitation at Dumont d'Urville, Adélie Land, East Antarctica: The APRES3 Field Campaigns Dataset. Earth Syst. Sci. Data 2018, 10, 1605-1612.

(51) Galbán-Malagón, C.; Cabrerizo, A.; Caballero, G.; Dachs, J. Atmospheric Occurrence and Deposition of Hexachlorobenzene and Hexachlorocyclohexanes in the Southern Ocean and Antarctic Peninsula. Atmos. Environ. 2013, 80, 41-49.

(52) Casal, P.; Casas, G.; Vila-Costa, M.; Cabrerizo, A.; Pizarro, M.; Jiménez, B.; Dachs, J. Snow Amplification of Persistent Organic Pollutants at Coastal Antarctica. Environ. Sci. Technol. 2019, 53, $8872-8882$.

(53) Muir, D.; Savinova, T.; Savinov, V.; Alexeeva, L.; Potelov, V.; Svetochev, V. Bioaccumulation of PCBs and Chlorinated Pesticides in Seals, Fishes and Invertebrates from the White Sea, Russia. Sci. Total Environ. 2003, 306, 111-131.

(54) Geisz, H. N.; Dickhut, R. M.; Cochran, M. A.; Fraser, W. R.; Ducklow, H. W. Melting Glaciers: A Probable Source of DDT to the Antarctic Marine Ecosystem. Environ. Sci. Technol. 2008, 42, 39583962.

(55) Van den Brink, N.; Riddle, M.; Van den Heuvel-Greve, M.; Allison, I.; Snape, I.; van Franeker, J. A. Correspondence on Geisz et Al. Melting Glaciers: A Probable Source of DDT to the Antarctic Marine Ecosystem. Environ. Sci. Technol. 2009, 43, 3976-3977.

(56) Thurmond, F.; Trotter, J. Morphology and Biomechanics of the Microfibrillar Network of Sea Cucumber Dermis. J. Exp. Biol. 1996, 199, 1817-1828.

(57) McClintock, J. B.; Heine, J.; Slattery, M.; Weston, J. Biochemical and Energetic Composition, Population Biology, and Chemical Defense of the Antarctic Ascidian Cnemidocarpa Verrucosa Lesson. J. Exp. Mar. Bio. Ecol. 1991, 147, 163-175.

(58) Janosik, A. M.; Halanych, K. M. Unrecognized Antarctic Biodiversity: A Case Study of the Genus Odontaster (Odontasteridae; Asteroidea). Integr. Comp. Biol. 2010, 50, 981-992.

(59) Ruppert, E. E.; Fox, R. S.; Barnes, R. D. Invertebrate Zoology: A Functional Evolutionary Approach; Thomson-Brooks/Cole, 2004. 